\title{
HRTEM and SAED investigations of polytypism, stacking disorder, crystal growth, and vacancies in chlorites from subgreenschist facies outcrops
}

\author{
David Schmid ${ }^{1, *}$ and Kenneth J.T. Livi ${ }^{2}$ \\ ${ }^{1}$ Mineralogisch-Petrographisches Institut, University of Basel, 4056 Basel, Switzerland \\ ${ }^{2}$ Department of Earth and Planetary Sciences, Johns Hopkins University, Baltimore, Maryland 21218, U.S.A.
}

\begin{abstract}
Selected-area electron diffraction (SAED) combined with experimental and computed high-resolution transmission electron microscopy (HRTEM) images were used to investigate polytypism, stacking disorder, mixed layering, and vacancies in chlorites from subgreenschist facies outcrops of the Taveyanne Sandstone from the Helvetic nappes, Switzerland. SAED patterns reveal increased ordering of the stacking sequences in chlorite with increasing metamorphic grade. However, semi-randomness and rotational faults occur even if the SAED photographs imply a regular ordered stacking sequence. In diagenetic $\left(T=210-250{ }^{\circ} \mathrm{C}, P=2.1-2.2 \mathrm{kbar}\right)$ and anchizonal-grade outcrops $\left(T=270-300{ }^{\circ} \mathrm{C}, P\right.$ $<5 \mathrm{kbar}$ ) the polytypes Ibb and IIbb of chlorite were found, whereas in epizonal-grade samples $\left(T=300-360{ }^{\circ} \mathrm{C}, P<5 \mathrm{kbar}\right)$ the exclusive polytype is IIbb. Based on SAED and HRTEM images, a polytypic evaluation in one epizonal sample indicate that the monoclinic polytype IIbb-2 (55\%) occurs as frequently as the triclinic polytype IIbb-4 (45\%). Our samples suggest that by far the most important influence on polytypism and stacking disorder is temperature.

Vacancy clusters occur in the octahedral cation positions within the talc-like layers and brucite-like sheets. The M1 and M2 positions in the talc-like layers are affected more by the cation deficiencies than the M3 and M4 positions in the brucite-like sheets. We suggest that octahedral vacancies are a substantial feature in natural chlorites in rocks of the Taveyanne Sandstone.
\end{abstract}

\section{INTRODUCTION}

Chlorite is one of the most abundant sheet silicates in diagenetic and low-grade metamorphic rocks. The ideal structure of trioctahedral chlorite is characterized by a regular alternation of brucite-like (B) sheets and talc-like (T) layers. There are several arrangements of B-sheets and T-layers that produce the many one-layer polytypes of chlorite. Bailey and Brown (1962) showed that chlorites theoretically can be divided into 12 unique one-layer polytypes and 6 semi-random structural polytypes. Furthermore, many chlorite crystals contain stacking sequence disorder that cannot be explained simply by polytypism. These defects are due to random rotations and mixed layering defects (e.g., Veblen 1983; Bons and Schryvers 1989). A few studies have examined chlorite structures as a function of metamorphic grade in subgreenschist metamorphic terrains (e.g., Hayes 1970; Curtis et al. 1985; Whittle 1986; Walker 1989; de Caritat et al. 1993; Walker 1993), but most studies are based on Xray diffraction techniques that are useful for identifying the polytype of perfect crystals. However, in the case of

\footnotetext{
* Present address: CRMC2-CNRS, Campus de Luminy, Case 913, 13288 Marseille, Cedex 9, France.

E-mail: schmidt@crmc2.univ-mrs.fr
}

disordered crystals, they only yield information on the average structure of the crystal (Bailey 1988). Most chlorite specimens contain structural disorder that can be best studied by high-resolution transmission electron microscopy (HRTEM) and selected-area electron diffraction (SAED) techniques (e.g., Veblen 1983; Spinnler et al. 1984; Bons and Schryvers 1989), but computer simulations are necessary for the correct interpretation of HRTEM images and SAED patterns.

In this study, we used HRTEM in combination with computer simulations and SAED to (1) determine the polytype and the extent of stacking disorder as a function of metamorphic grade in subgreenschist facies areas; (2) study the transformation of intercalated phases into chlorite; and (3) investigate the presence of point defects within the chlorite structure that might have an influence on its non-stoichiometric behavior. This study takes advantage of the well-known metamorphic conditions (Coombs et al. 1976; Kisch 1980; Bussy and Epard 1982, 1984; Burkhard 1988; Dietrich and Casey 1989; Schmidt et al. 1997) of the area where the investigated chloritebearing specimens were collected. Recent studies have given a detailed description of the chemical composition of chlorite and the interlayered phases from the same rock chips as used here, derived by electron microprobe ana- 
lyses (EMPA) (Schmidt et al. 1997), HRTEM, and analytical electron microscopy (AEM) (Schmidt 1997).

\section{Chlorite structure}

The ideal structure of trioctahedral chlorite is characterized by a regular alternation of $\mathrm{B}$ sheets $\left(\mathrm{R}^{2+}, \mathrm{R}^{3+}\right)_{3}(\mathrm{OH})_{6}$ and $\mathrm{T}$ layers $\left(\mathrm{R}^{2+}, \mathrm{R}^{3+}\right)_{3}\left(\mathrm{Si}_{4-\mathrm{x}} \mathrm{Al}_{\mathrm{x}}\right) \mathrm{O}_{10}(\mathrm{OH})_{2}$. Within the $\mathrm{T}$ layer, there is a displacement of magnitude $1 / 3[100]$ that defines the talc-stagger (Bailey and Brown 1962). By definition, the talc-stagger should lie in the (001) plane and its direction should be parallel to [100] to facilitate the interpretation of HRTEM images according to Spinnler et al. (1984). This procedure helps to overcome the problem that the talc-stagger is not always in the same orientation for all 12 unique one-layer polytypes with respect to their crystallographic systems. In addition, 6 structures exist having semi-random stacking sequences, designated as Iaa, Iba, Ibb, IIaa, IIab, IIbb.

There are only a few studies that describe the deformation mechanism of chlorites (e.g., Spinnler et al. 1984; Bons 1988; Bons and Schryvers 1989). Spinnler et al. (1984) and Bons and Schryvers (1989) observed the occurrence of stacking faults caused by a shift of magnitude $1 / 3[010]$ parallel to the (001)-basal plane that occurred at the level of the T layer and B sheet. Spinnler et al. (1984) computed HRTEM images of all one-layer polytypes projected in $\langle 100\rangle$ and $\langle 110\rangle$ directions. They suggested that the HRTEM images can be used to determine the projected shift vectors across the $\mathrm{T}$ layers and $\mathrm{B}$ sheets. The shifts across the $\mathrm{T}$ layers and $\mathrm{B}$ sheets can be described by the symbols $\mathrm{T}_{0}, \mathrm{~T}_{+}, \mathrm{T}_{-}$and $\mathrm{B}_{0}, \mathrm{~B}_{+}, \mathrm{B}_{-}$. The signs under the letters describe the relative shifts that occur within these layers. For instance, $T_{-}$indicates that the upper tetrahedral sheet of the TOT layer in the HRTEM image is displaced to the left by a shift vector with the magnitude $-1 / 6[010]$ with respect to the lower tetrahedral sheet if viewing down along the [110] direction. $\mathrm{B}_{0}$ is used if the upper tetrahedral sheet and the lower tetrahedral sheet of an adjacent TB unit are opposite to each other (first example in Fig. 1).

Spinnler et al. (1984) could show that five distinct projections resulted from viewing down one of the $<100>$ and $<110>$ directions if all possible one-layer polytypes were considered. They concluded that the chlorite shift vectors can be used to distinguish between several of the one-layer polytypes. However, because HRTEM images are projections of the chlorite structures, more than one structure can produce the same image. Therefore, complete specification of chlorite polytypism requires either $\mathrm{X}$-ray diffraction analysis or HRTEM images from at least two different major zones of the same crystal. All possible chlorite shift vectors of the one-layer chlorite polytypes as seen down the [100], [110], and [110] axes are listed in the appendix.

\section{SAMPLE DESCRIPTION AND METHODS}

\section{Geological setting and sample mineralogy}

The chlorite-bearing Taveyanne formation from the Helvetic nappes in Switzerland is part of a sequence of

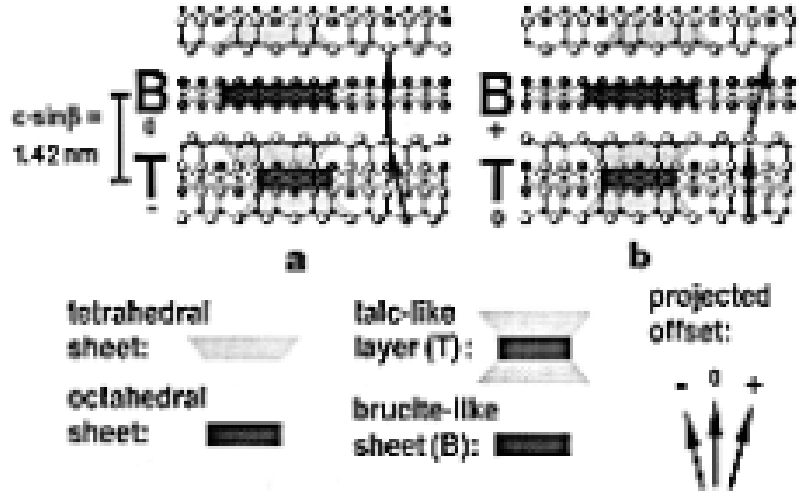

Figure 1. Idealized schematic diagram of the chlorite structure viewed parallel to the layers. I-beams and stacking vectors are used to simplify the structural components of chlorite: (a) the magnitude of the projected offset is $-b / 6$ across the $\mathrm{T}$ layer and 0 across the B sheet. (b) magnitude of the projected offset is 0 across the $\mathrm{T}$ layer and $+b / 6$ across the $\mathrm{B}$ sheet.

early Oligocene sediments. The rocks are mainly composed of andesitic volcanic fragments that have their origin in the volcanic activity that occurred during the subduction/collision event of the Alpine orogenic phase (Waibel 1993). Subsequently, the rocks underwent regional metamorphism. Based on mineral assemblages found in the Taveyanne greywacke, the metamorphic grade ranges from zeolite to lower greenschist facies (Coombs et al. 1976; Kisch 1980; Bussy and Epard 1982, 1984; Schmidt et al. 1997). Schmidt et al. (1997) compared different metamorphic facies with illite crystallinity (IC) indexes of adjacent shales (Table 1), and correlated mineralogy and IC with temperatures and pressures derived from fluid inclusion data, stable isotope geothermometry, and thermodynamic analysis of the Taveyanne greywacke samples. In addition, Ramsay (1981) and Dietrich and Casey (1989) noted a strong increase of strain state linked with the increase of the metamorphic grade in this region. Six representative samples were selected from a prograde sequence of the Taveyanne sandstone.

The mineralogy of the Taveyanne greywacke is mainly composed of the mineral assemblage albite, chlorite, calcite, K-white mica, quartz, titanite, \pm hornblende, \pm clinopyroxene, \pm laumontite, \pm prehnite, \pm pumpellyite, \pm actinolite, and \pm epidote. Authigenic chlorite is an ubiquitous phase in all metamorphic stages. In diagenetic and anchizonal-grade samples, authigenic chlorite occurs in the matrix and as a dense overgrowth on volcanogenic clasts. In epizonal-grade samples, chlorite is the most abundant mineral in the matrix of the Taveyanne greywacke. As a first approximation, the formulae of epizonal chlorites can be expressed by $\mathrm{Fe}_{2.55} \mathrm{Mg}_{2.25} \mathrm{Al}_{1.2} \mathrm{Si}_{2.8} \mathrm{Al}_{1.2} \mathrm{O}_{10}$ $(\mathrm{OH})_{8}$ based on EMPA of samples from the study area (Schmidt et al. 1997). In addition, EMPA showed a correlation between $\Sigma(\mathrm{Ca}+\mathrm{Na}+\mathrm{K})$ in chlorite and the calculated occupancy of the octahedral sites (Schmidt et al. 1997; Schmidt 1997). Therefore, these authors sug- 
TABLE 1. Comparison between mineral facies and metamorphic zones derived from illite crystallinity (IC)

\begin{tabular}{llllrl}
\hline \hline Index no. & Locality & Facies & Zone & $I_{\text {mean }}^{*}$ & $T\left({ }^{*} \mathrm{C}\right) \dagger$ \\
\hline FB 108 & Diablerets & Zeolite & Diagenesis & $0.48 \pm 0.04(6)$ & $210-250$ \\
EP 3 & Olden & Zeolite & Diag./Anch. & $0.41 \pm 0.01(3)$ & $2.1-2.2$ \\
EP 29 & Le Sex & Prh-Pmp & Anchizone & $0.29 \pm 0.03(3)$ & $2.1-2.2$ \\
EP 23 & Chumme & Prh-Pmp & Anchizone & $0.29 \pm 0.03(6)$ & $270-300$ \\
Z 1 & Bublet & Pmp-Act & Epizone & $0.23 \pm 0.01(2)$ & $270-300$ \\
GPB 171 & Wiler & Pmp-Act & Epizone & $0.21(1)$ & $300-360$ \\
\hline
\end{tabular}

Notes: Inferred temperature range (based on fluid inclusion investigations, stable isotope geothermometry and thermodynamic calculations, modified after Schmidt et al. 1997). Note that according to Kübler (1984), the limiting values for the low-grade and high-grade boundary of the anchizone are $0.42^{\circ}$ and $0.25^{\circ} \Delta 2 \Theta$ CuK $\alpha$, respectively.

* Averaged illite crystallinity indexes $\left[{ }^{\circ} \Delta 2 \Theta \pm 1 \sigma\right]$ after Kübler (1984) for air dried samples. $(n)=$ number of samples.

$\dagger$ Inferred temperature ranges and estimated pressures (see text and Schmidt et al. 1997).

gested a minor influence of intergrown smectite, especially in diagenetic and anchizonal chlorites.

\section{Sample preparation and analytical methods}

Samples of Table 1 were investigated by a JEOL 8600 Superprobe at the University of Basel and at the Johns Hopkins University in Baltimore. Two samples of each metamorphic zone, as defined by IC, were made into doubly polished thin sections mounted with the heat-sensitive adhesive Crystalbond 509, for HRTEM and SAED work. Two-dimensional lattice images using HRTEM technique were obtained using a Philips 420ST microscope operating at $120 \mathrm{kV}$ and using a $0.09 \mathrm{~nm}^{-1}$ objective aperture. Electron-transparent foils were made from fragments of petrographic thin-sections using an argon ion mill, followed by a light coating of carbon. Diffraction and imaging techniques were similar to those listed in Baronnet (1992).

In this study, the concept of Spinnler et al. (1984) was slightly modified using a combination of SAED and HRTEM to determine the one-layer polytype in chlorite. Chlorite has a pseudo-hexagonal symmetry in the (001) plane (Fig. 2a). SAED patterns were taken along the [010] direction or along one of its pseudo-equivalent directions in $<310>$. Additionally, SAED patterns were taken down one of the [100], [110] or [110] axes that occur in between the forms $<010>$ and $<310>$. Note that only for a few samples was it possible for SAED patterns of these two non-equivalent major zone axes to be taken from the same crystal. In most cases these SAED patterns were taken from different crystals, but in the same TEM sample.

\section{Computer simulations}

Computer simulations were performed using the computer programs EMS-A from Stadelmann (1987) and MacTempasPCC. In Figure $2 b$, an experimental image is compared with a calculated image with a thickness of $\sim 3.0 \mathrm{~nm}$ and defocus value of $-65.0 \mathrm{~nm}$ that were computed for the IIbb-4 polytype viewed along the [110] direction. The computed image is in good agreement with the observed HRTEM image. The B sheet is represented as a dark band whereas the $\mathrm{T}$ layer is shown as a zigzag pattern between the $\mathrm{B}$ sheets. The tetrahedra of the $\mathrm{T}$ layers are visible in the upper and lower part of the zigzag pattern as dark spots. Within the $\mathrm{T}$ layers, the projected upper tetrahedra are shifted $-\frac{1}{6}[010]$ to the left with respect to the projected lower tetrahedra. In contrast, tetrahedra of the $\mathrm{T}$ layers on opposing sides of the $\mathrm{B}$ sheets are always exactly opposite to each other. The stacking sequence may then be termed $\mathrm{T}_{-} \mathrm{B}_{0}$. To interpret the image more easily, the white spots that occur between the tetrahedra were used to determine the relative shifts across the layer sequences, instead of the dark spots. Relative shifts across the $\mathrm{B}$ sheets and $\mathrm{T}$ layers were marked with white arrows. Images were calculated as a function of focus (defocus $=130.0 \mathrm{~nm}$ to $-330.0 \mathrm{~nm}$ ) and thickness ( $3.0 \mathrm{~nm}$ to $21.0 \mathrm{~nm}$ ) in both $<100>$ and $<110>$ directions to ensure that the images taken close to Scherzer focus were unique. Image computations of a IIbb-4 polytype along the [110] direction showed that samples with a thickness $<9.0 \mathrm{~nm}$ observed under defocus conditions between $-45.0 \mathrm{~nm}$ and $-85.0 \mathrm{~nm}$ are still interpretable with respect to the chlorite shift vectors (Fig. 2c).

SAED patterns of chlorite polytypes were calculated with a thickness of $\sim 3.0 \mathrm{~nm}$ and defocus value of -65.0 $\mathrm{nm}$ viewed down the [010] axis (Fig. 2d). For simplicity, only the natural-occurring structural polytypes were taken into account. This approach reduced the number of considered structural polytypes from six to four (Iaa, Iba, Ibb, IIbb). The number of structural polytypes is equal to the number of the semi-random polytypes. The computed SAED patterns include two major reciprocal axes: $\mathbf{c}^{*}$ and $\mathbf{a}^{*}$. Note that SAED patterns, which are obtained along one of the pseudo-symmetrically related axes by $60^{\circ}$ rotations around $\mathbf{c}^{*}$ (e.g., [310], [310]) have similar intensities, but intensities may be mirrored perpendicular to c* $^{*}$. Based on the angle between the major reciprocal axes as well as the intensities of the $20 l$ row, the different structural types can be identified. Because of sample thickness, misorientations, crystal lattice distortion, polycrystalline chlorite aggregation, and irregularities in the stacking sequences more than $2 / 3$ of all SAED patterns were discarded.

\section{RESULTS}

SAED patterns along the $[010],[310],[3 \overline{10}]$ axes

A few diffraction patterns from the diagenetic and anchizone-grade samples of chlorite taken in $<010>$ or 

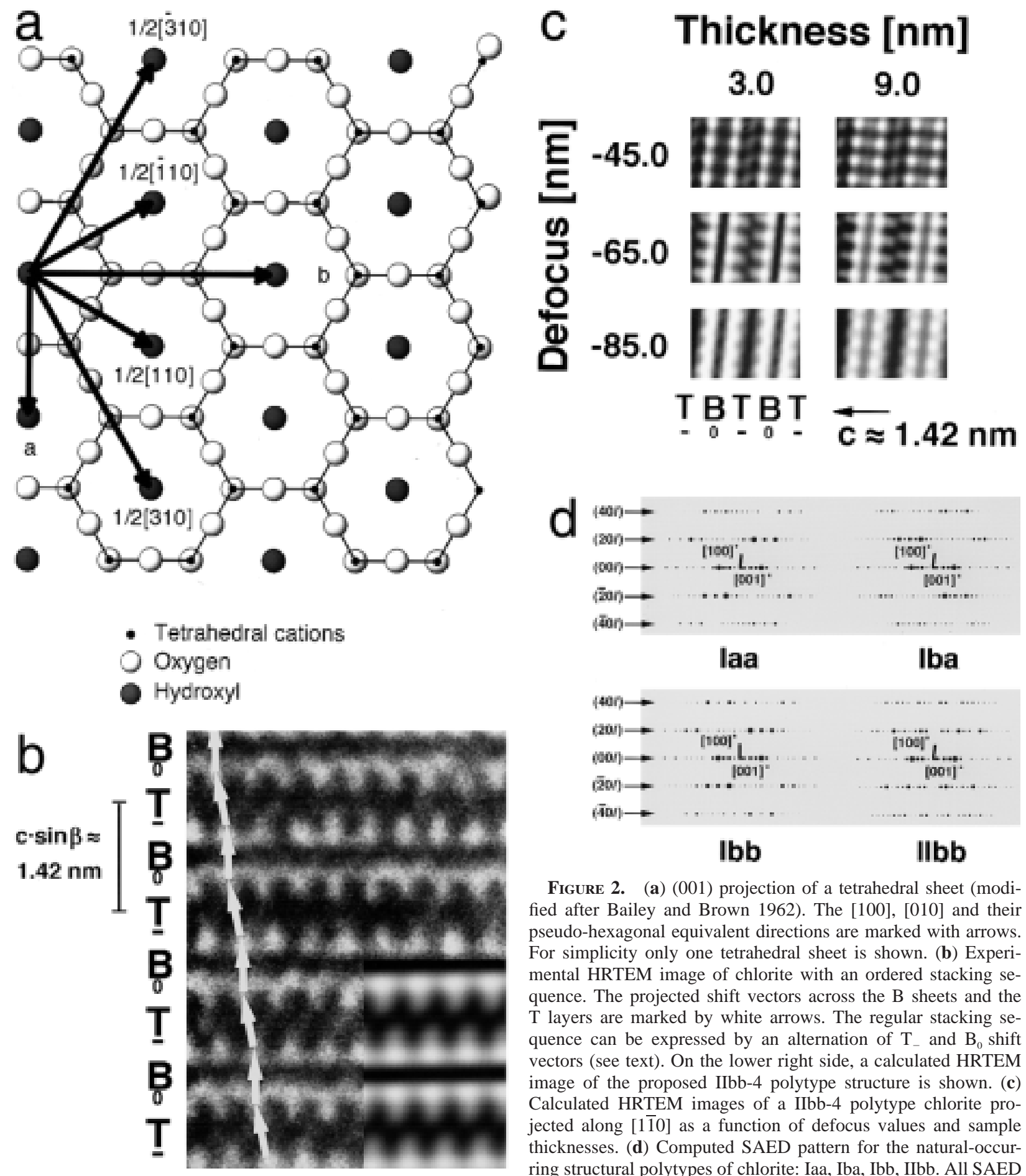

Figure 2. (a) (001) projection of a tetrahedral sheet (modified after Bailey and Brown 1962). The [100], [010] and their pseudo-hexagonal equivalent directions are marked with arrows. For simplicity only one tetrahedral sheet is shown. (b) Experimental HRTEM image of chlorite with an ordered stacking sequence. The projected shift vectors across the B sheets and the $\mathrm{T}$ layers are marked by white arrows. The regular stacking sequence can be expressed by an alternation of $T_{-}$and $B_{0}$ shift vectors (see text). On the lower right side, a calculated HRTEM image of the proposed IIbb-4 polytype structure is shown. (c) Calculated HRTEM images of a IIbb-4 polytype chlorite projected along [1힐 as a function of defocus values and sample thicknesses. (d) Computed SAED pattern for the natural-occurring structural polytypes of chlorite: Iaa, Iba, Ibb, IIbb. All SAED patterns were calculated for chlorites viewing down the [010] direction (defocus $=-6.5 \mathrm{~nm}$, thickness $=\sim 3.0 \mathrm{~nm}$ ).

$<310>$ directions indicate abundant irregular stacking disorder. These diffraction patterns show streaked reflections, except for $(00 l)$ reflections. In contrast, SAED patterns of chlorites from the epizone do not reveal any

streaking in $<010>$ or $<310>$ patterns. Some SAED patterns of diagenetic chlorites reveal additional reflections in the $[00 l]$ row with calculated $d$ spacings of $0.9-1.0$ $\mathrm{nm}$. EMP and AEM data from these samples suggest that 
the additional spots are caused by intercalated smectite (collapsed) or mica-layer packets (Schmidt et al. 1997; Schmidt 1997).

Two different structural types could be identified unequivocally. Diffraction patterns show that the Ibb (Fig. 3a) and IIbb (Figs. 3b and 3c) structural polytypes occur in samples from the Taveyanne Sandstone. Experimental intensities of the reflections were compared with calculated intensities. Most of the experimental intensities in Figure 3 match the calculated intensities. For the Ibb SAED photograph, some reflections do not compare well with calculated intensities. However, because only the Ibb polytype contains an angle of $90^{\circ}$ between the major axes $\left(=\mathbf{a}^{*},[1 \overline{\mathbf{3}} \mathbf{0}]^{*}\right.$ or $[\overline{\mathbf{1 3 0}}]^{*}$ vs. $\left.\mathbf{c}^{*}\right)$, the structural polytype Ibb can be determined unequivocally.

SAED patterns were grouped together as a function of metamorphic grade in Figure 4a. Type Ibb is the most common structural polytype that could be identified in samples FB108 and EP 3. With increasing metamorphic grade, the occurrence of type Ibb decreases, and in the epizone, only the type IIbb could be identified. Several diffraction patterns without a $90^{\circ}$ angle between major axes were discarded because they could not be assigned to one of the four different structural polytypes due to the reasons cited above.

\section{Patterns taken along the [100],[110],[110] axes}

Gradual variations of the SAED patterns were observed from discrete spots as displayed in Figure 3c (arrows 2) to continuous streaks for reflections with $\mathrm{k} \neq 3 \mathrm{n}$. In Figure 4b, SAED patterns were grouped based on the degree of disorder indicated by the $\mathrm{k} \neq 3 \mathrm{n}$ reflections. The first group includes diffraction patterns with continuous streaks and those with strong streaks in between intensity maximum. The second group comprise diffraction patterns with discrete spots that may also include faint streaking. Only streaked diffraction patterns (for $\mathrm{k}$ $\neq 3 n$ ) were found in samples from the diagenesis (Fig. 4b). Non-streaked SAED patterns were more abundant in chlorite samples from the epizone.

Twinning was observed as $\pm 30^{\circ}$ layer rotations similar to Veblen (1983). An epizonal-grade chlorite grain contains areas with two distinct orientations (Fig. 3c): one in the [010] direction indicating a IIbb structural polytype and one in the [110] direction, assuming a IIbb structural polytype. The angle between [010] and [110] axes is approximately $30^{\circ}$, which can be inferred from Figure $2 \mathrm{a}$.

\section{HRTEM images}

HRTEM images of chlorite from anchizonal rocks contain a mixture of high- and low-grade chlorite crystals. Therefore, we focused our attention on the diagenetic and epizonal-grade samples.

Stacking disorder in chlorites from the diagenetic realm. A two-dimensional HRTEM image from sample EP3/50 of a disordered stacking sequence taken mainly along of one of the $<100>$ or $<110>$ axes (Fig. 5a) shows intercalations of $1.0 \mathrm{~nm}$ layers, but contained only

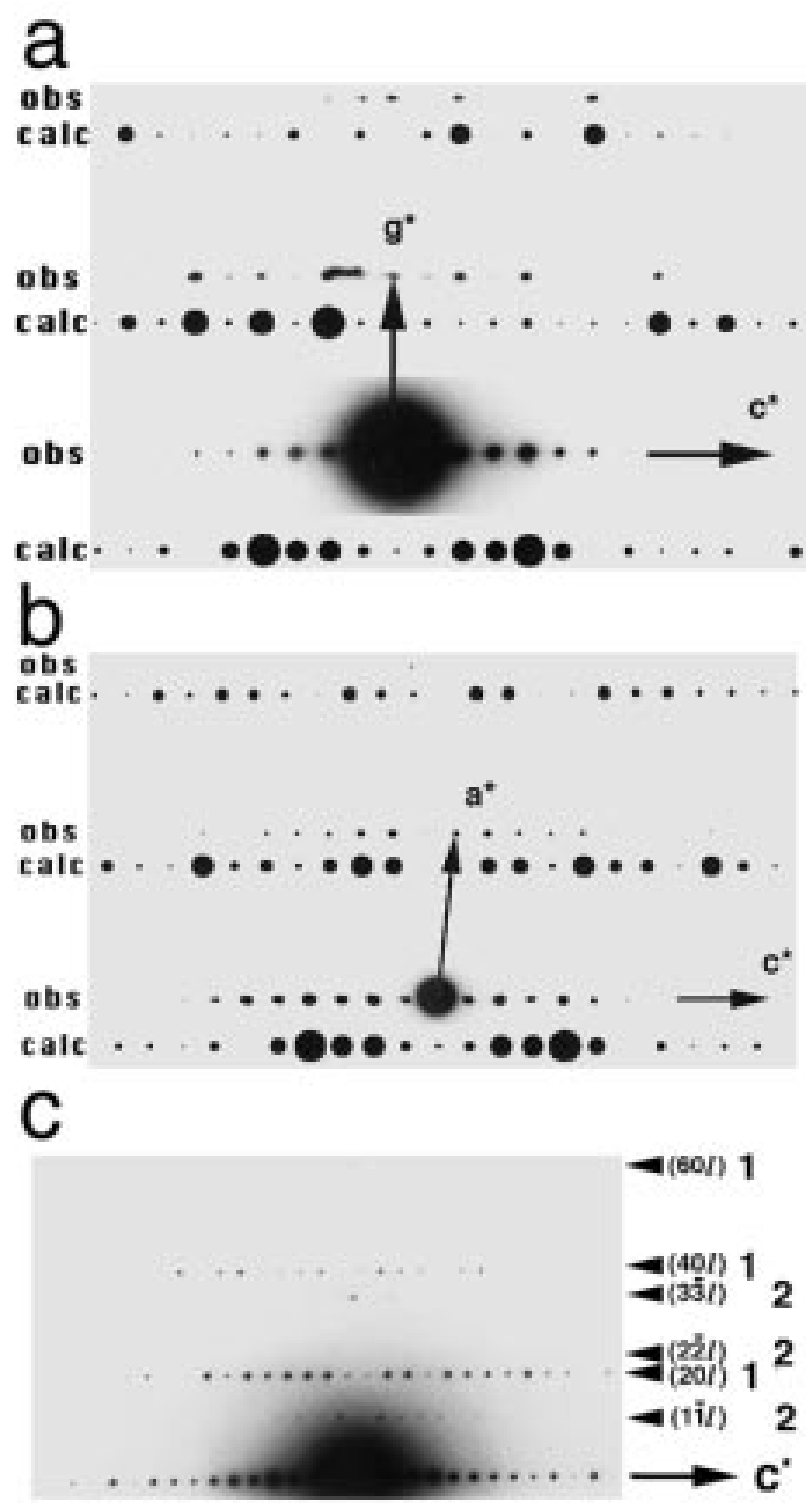

Figure 3. (a) SAED photograph of a diagenetic chlorite crystal that is mainly oriented with its axis parallel to the electron beam. The orthogonal symmetry of the diffraction pattern is consistent with the Ibb polytype (see text). Differences between observed (obs) and calculated (calc) intensities may be due to sample thickness and irregularities of the stacking sequence, for instance, rotational faults around $\pm 120^{\circ}$. Due to these assumed rotational faults, the reciprocal $\mathbf{g}^{*}$ vector may belong to the $[100]^{*},[1 \overline{3} 0]^{*}$, and $[\overline{\mathbf{1 3 0}}]$ axes. Note that the calculated SAED pattern is a [310] pattern, which is virtually identical to a [100] pattern but mirrored along $\mathbf{a}^{*}$. (b) SAED photograph taken along the [010] axis from an epizonal-grade chlorite. The non-orthogonal symmetry $\left(\beta \approx 97^{\circ}\right)$ and intensities of the reflections are consistent with the IIbb polytype. (c) SAED photograph showing $30^{\circ}$ rotational twinning in an epizonal-grade chlorite. Rows marked by " 1 " were taken along in [010] direction of the structural polytype IIbb, whereas rows marked by " 2 " were taken along the [110] direction and are presumably of the IIbb structural polytype. 
limited structural information. One TB unit and one 1.0 $\mathrm{nm}$ layer may be grouped to a $2.4 \mathrm{~nm}$ layer pair. Earlier studies have shown for this sample that the $1.0 \mathrm{~nm}$ layers are probably smectite based on EMPA (Schmidt et al. 1997) and combined HRTEM images and AEM analyses (Schmidt 1997). Hence, the $2.4 \mathrm{~nm}$ layer pairs suggest a corrensite-like intercalation.

The chlorite shift vectors in this sample tend to change their directions over short distances along the basal plane within the chlorite units. At area 2 of Figure 5a, the chlorite shift vector can be best described by $T_{0} B_{0}$ in terms of Spinnler et al. (1984). A few nanometers to the left (point 1), the image dramatically changes and the resulting cross fringes do not match any computed images for chlorite close to Scherzer focus over a range of thicknesses $(<21.0 \mathrm{~nm})$ using the $<100>$ or $<110>$ projections. Fourier analysis of these areas showed the same spacing of the reflections in calculated diffraction patterns, but the reflection intensities were different. One explanation for this is that both images belong to one zone axis, but with slightly different orientations due to lattice strain.

The experimental SAED pattern associated with Figure 5 a contains streaks in the $\mathrm{k} \neq 3 \mathrm{n}$ rows. Reflections that belong to more than one zone axis are also present in the SAED pattern indicating that more than one crystal orientation is present. In conjunction with regions where cross fringes were not visible (e.g., area marked by question marks), determination of the chlorite shift vectors for diagenetic-grade samples is difficult. As a result, shift vectors were determined only for epizone-grade samples.

Stacking disorder in chlorites from the epizonalgrade realm. HRTEM images show that stacking sequences in chlorite structures from epizonal-grade rocks can be grouped into three categories (see Spinnler et al. 1984): (1) regularly ordered stacking sequences with all shift vectors having the same sign, (2) semi-random stacking sequences with three distinct directions of projected shift vectors occurring within the B sheets, and (3) presumable $\pm 120^{\circ}$ rotational faults within the $\mathrm{T}$ layers. Category 1 is illustrated in Figure 2b, which shows a regularly ordered stacking sequence. The sign of the projected shift vectors across the T layers is negative, whereas no shift occurs across the B sheets. As mentioned before, the stacking sequence of this area can be described by the notation $T_{-} B_{0}$. Categories 2 and 3 are shown in Figure $5 b$. On the right side of Figure $5 b$, alternation of $\mathrm{B}$ sheets and $\mathrm{T}$ layers are visible, except for the middle part where two adjacent $T$ layers occur. In the center of the image, an additional $\mathrm{B}_{0}$ sheet appears between the two adjacent $\mathrm{T}$ layers causing strain contrast (dark area) to extend several nanometers into the upper part of the image. On the left side, there is a regular alternation of $\mathrm{B}$ sheets and $\mathrm{T}$ layers. In the upper left part of the image, the T-layer shift vectors are always positive, but the sign of the B-sheet shift vectors change. In the lower part of the image, two $\mathrm{T}_{-}$layers indicate that rotational faults within the semi-random stacking sequence occur. Al-
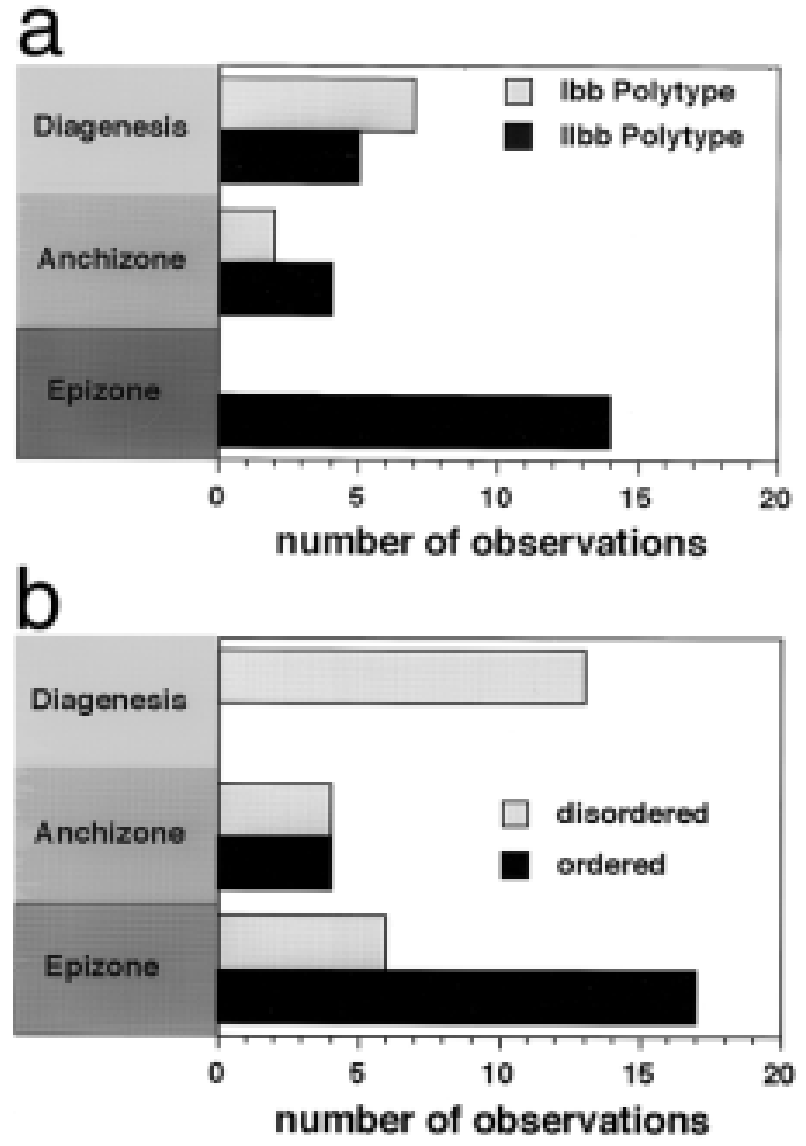

Figure 4. (a) Number of observations of the structural polytypes determined from SAED patterns in the [010], [310], or [310] orientations. (b) Number of observations of disordering in the stacking sequences determined from SAED patterns taken in the [100], [110], or [1 $\overline{1} 0]$ orientations (see text).

though the termination of the B sheet is coupled with stress within the lattice, the stacking sequence is not altered from the left to the right sides. The inset illustrates the structure around the adjacent $\mathrm{T}$ layers. We have observed that rotational faults in the $\mathrm{T}$ layers are less common than semi-random stacking faults in the B sheets.

The middle of a two-dimensional HRTEM image of a nearly regularly ordered $\mathrm{T}_{-} \mathrm{B}_{0}$ stacking sequence of chlorite (Fig. 5c) has two single $0.7 \mathrm{~nm}$ serpentine-like layers, hereafter designated " $S$ " layers. Note that the sign under the letter $\mathrm{S}$ has the same meaning as compared to the TB shift vectors (Fig. 1). Intercalated between these $S$ layers is one B sheet. The inset of Figure $5 \mathrm{c}$ illustrates the structure around the $\mathrm{S}$ layers. This diagram assumes that the white dots fall in the plane of the tetrahedral sites. This creates a structure that is composed of alternating tetrahedral and octahedral sheets. In addition, the diagram shows a proposed layer transformation process (see Baronnet 1992; Banfield and Bailey 1996). The diagram assumes that only the tetrahedral sheets migrate during the transformation process of the layers. Note, that the stack- 

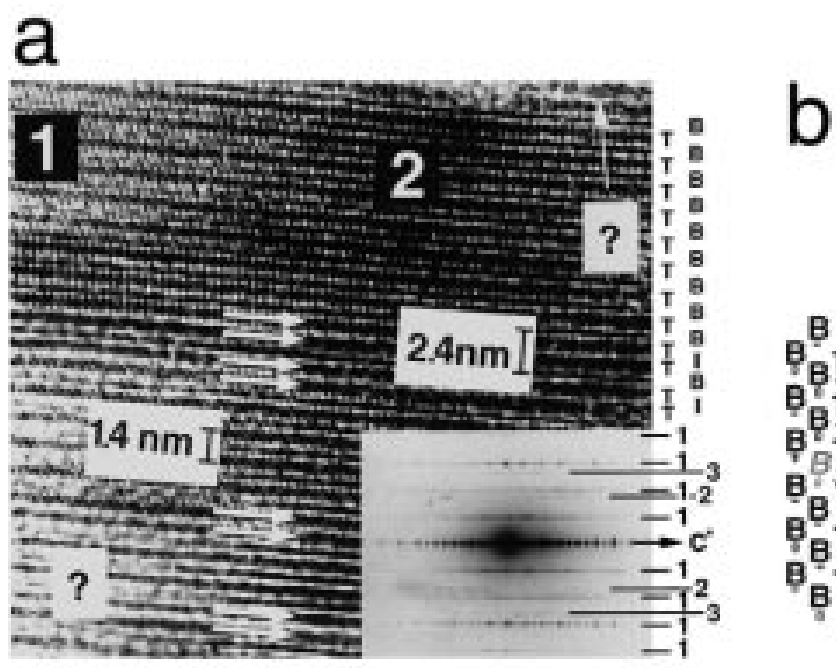

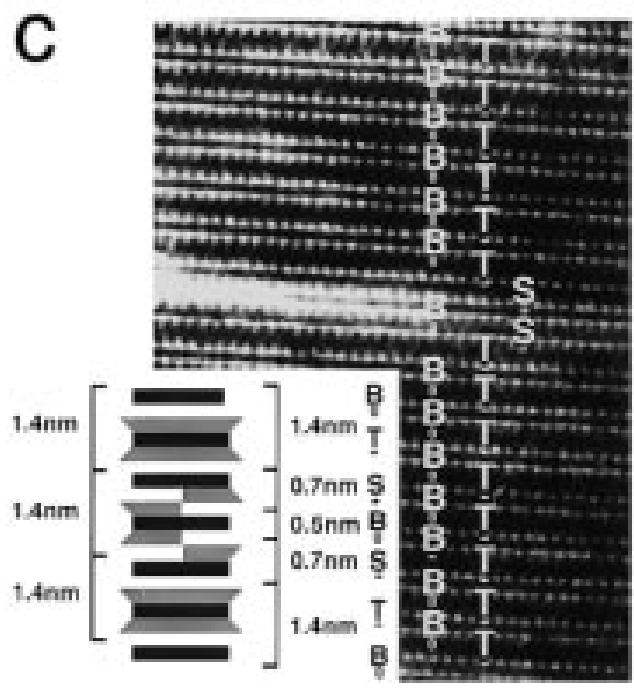

Figure 5. (a) HRTEM image of chloritic material from a diagenetic outcrop. Distortions in the chlorite units are, in part, caused by intercalated $1 \mathrm{~nm}$ layers. Two adjacent $1 \mathrm{~nm}$ layers are marked by white arrows $(\mathrm{T}=$ talc-like layers; $\mathrm{B}=$ brucitelike sheets; I = interlayer sites). In the upper left part of the image labeled " 1 ", the chlorite structure is distorted as compared to the upper middle part labeled " 2 ". Areas with one-dimensional information are marked with question marks. In the inset, a SAED pattern is shown indicating stacking disorder in chlorite. The chlorite layers are oriented parallel to the electron beam with their [100] (rows "1"), [010] (rows "2"), or [210] (rows “3”) axes (or with one of the pseudo-hexagonal related axes). (b) HRTEM image of an irregular stacking sequence. In the middle of the image, an edge dislocation of a $\mathrm{B}$ sheet causes distortion

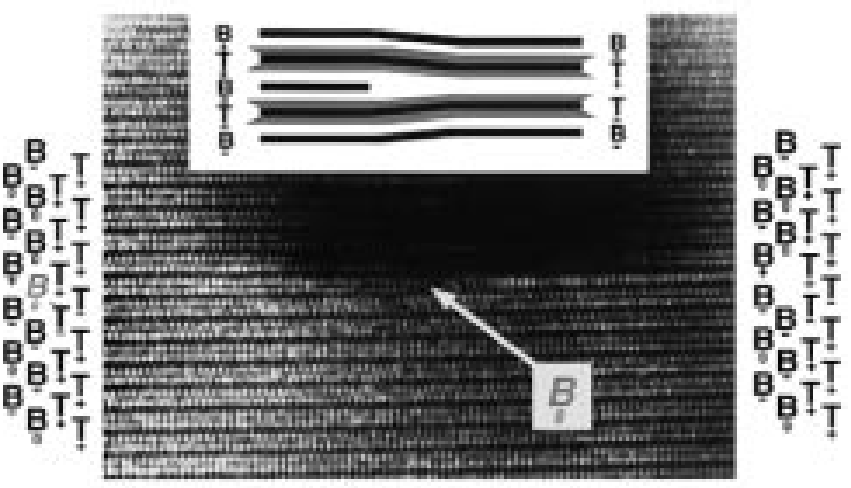

ing sequence adjacent to the $\mathrm{S}$ layers is undisturbed. The HRTEM image also shows the effect of beam damage. The $\mathrm{B}$ sheet between the $\mathrm{S}$ layers has been damaged selectively, indicating that it is less stable than surrounding $B$ sheets.
S-layer transformations can be observed in Figure 5d. In the upper right side of the image (area 1), two $S$ layers marked with white arrows are visible within a semi-random stacking sequence of chlorite. In the center of the image, structural details become blurred. At the lower left 
side of the image (area 2), only alternating $\mathrm{T}$ layers and $\mathrm{B}$ sheets are visible. The observed stacking sequence is $\mathrm{T}_{+} \mathrm{B}_{-}, \mathrm{T}_{+} \mathrm{B}_{+}, \mathrm{T}_{+} \mathrm{B}_{+}, \mathrm{T}_{+} \mathrm{B}_{-}$. As shown in the inset, one $\mathrm{TB}$ unit replaces two serpentine layers. The stacking sequence is not altered as a consequence of the layer transformation.

\section{Vacancies}

In the very thin part of sample GPB 171/61, abnormally strong differences in brightness within $\mathrm{T}$ layers and $\mathrm{B}$ sheets were found in a pure $\mathrm{T}_{-} \mathrm{B}_{0}$ stacking sequence of chlorite (Fig. 6). To determine the cause for the change in contrast, experimental HRTEM images (area II) were compared with computed HRTEM images (area I) for a IIbb chlorite structure containing octahedral site vacancies. Detailed information about the computer simulations of defects in chlorite is given in the appendix. All simulations of defects were computed at a defocus of -65.0 $\mathrm{nm}$ with a thickness of $\sim 3.0 \mathrm{~nm}$ similar to Figure $2 \mathrm{a}$. Note, that images taken at this special defocus setting of the microscope are often referred to as imaging code, by which many defects in the perfect structure can be directly interpreted (e.g., Bons and Schryvers 1989).

In area II of Figure 6a, an experimental HRTEM image shows an alternating $\mathrm{T}_{-} \mathrm{B}_{0}$ sequence. An abnormal white spot is visible between the tetrahedral columns (arrow 1). Computer simulations of chlorite vacancies indicate that a cluster of octahedral vacancies in the M2 position may be responsible for differences in brightness. Likewise, a white spot within the dark band over a B sheet (arrow 2) indicates that a deficiency of M3 and M4 octahedral cations may be present. Another example is given in Figure $6 \mathrm{~b}$ that shows an experimental $\mathrm{T}$ layer with abnormal brightness in the octahedral sheet (area II). The anomalous white areas within the $\mathrm{T}$ layers can be simulated by a combination of M1 and M2 vacancies. A qualitative evaluation of the experimental HRTEM images from sample GPB 171/61 indicates that the occurrence of M1 and M2 vacancies within the T layers is more common than M3 and M4 vacancies in the B sheets. Simulations for tetrahedral vacancies were also calculated. However, clusters of point defects that can be simulated by tetrahedral vacancies were only found in the damaged area close to the rim of the sample where the ion-milling process and beam damage have destroyed parts of the chlorite structures.

\section{Discussion}

\section{Ordering of the stacking sequence in chlorite}

SAED patterns and HRTEM images show that diagenetic chlorites from the Taveyanne Sandstone ( $\mathrm{T}=210$ $250{ }^{\circ} \mathrm{C}$ ) are highly disordered in their stacking sequences and both structural polytypes [Ibb $\left(\beta=90^{\circ}\right)$ and IIbb $(\beta$ $\approx 97^{\circ}$ )] can be found (Fig. 4a). However, complete specification of the unique one-layer polytypes was not possible due to streaked reflections $(k \neq 3 n)$ in SAED patterns in the [100], [110], or [1ํㅣㄹ direction. In addition, correct interpretation of the stacking sequence shift vec-

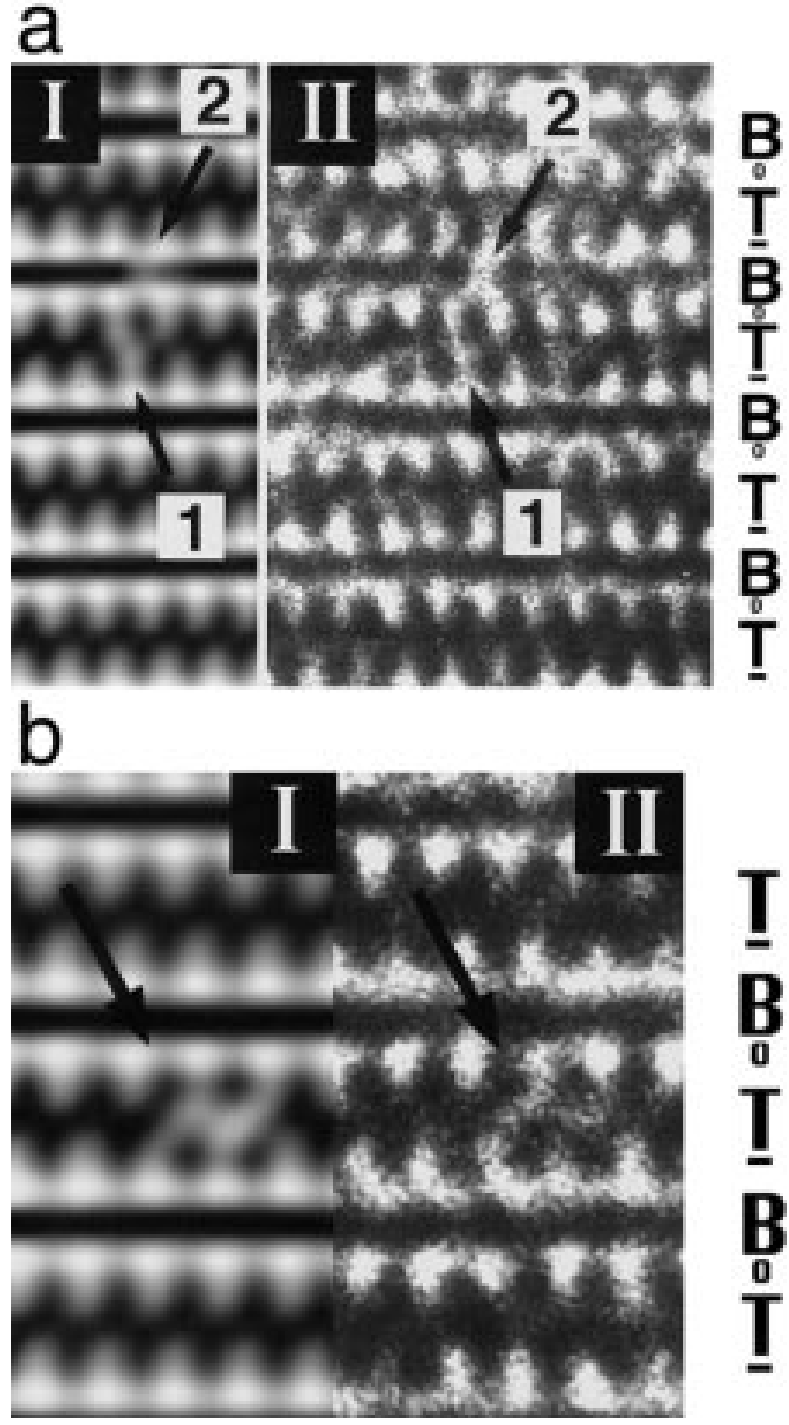

Figure 6. (a) (I) Computed HRTEM image (defocus = $-65.0 \mathrm{~nm}$; thickness $\approx 3.0 \mathrm{~nm}$ ) of chlorite calculated along the [11̄0] axis. White spot 1 is due to calculations of the IIbb-4 polytype with M2 vacancies in the octahedral sheet of the T layer. White spot 2 was calculated with a deficiency of M3 and M4 cations in the B sheet. (II) Experimental HRTEM image taken close to Scherzer focus showing similar vacancy contrast. (b) (I) Computed HRTEM image (defocus $=-65.0 \mathrm{~nm}$; thickness $\approx 3.0 \mathrm{~nm}$ ) with a simulated vacancy cluster in the M1 and M2 positions of the T layer in chlorite calculated along the [1 $1 \overline{1} 0]$ axis. (II) Experimental HRTEM image taken close to Scherzer focus showing vacancy contrast.

tors was complicated by local distortions of the crystal lattice (Fig. 5a). Some SAED photographs that were tak-

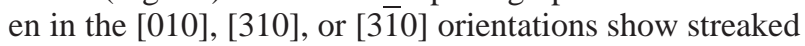
reflections. These crystals may include different structural polytypes within the selected area aperture or may contain random rotations of $\pm 120^{\circ}$ about $\mathbf{c}^{*}$. More than two thirds of our diffraction patterns could not be assigned to one of the 4 structural types that occurs in nature and 
other structural polytypes may be present, especially in the diagenetic realm. However, in most cases intensity distributions of the discarded diffraction patterns are more similar to those calculations for type-IIbb than to other structural polytypes. Therefore, it is possible that IIbb may be the most abundant chlorite polytype even in diagenetic outcrops (samples FB 108, EP 3).

In anchizonal-grade samples (EP 29, EP 23), SAED diffraction patterns and HRTEM images show that the degree of ordering in stacking sequences viewed down the [100], [110], or [11̄0] axes appear to be a mixture of low-grade and high-grade crystals. Such observations imply that the degree of ordering in the stacking sequences of chlorite may be best understood with respect to local differences in kinetic factors. These involve a great variety of parameters such as fluid/rock ratio, crystallographic orientation relative to the principle strain directions, transformation mechanisms, and the nature of starting materials.

In epizonal-grade samples (samples Z1, GPB 171), no streaking is observed in diffraction patterns taken along [010], [310], or [310]. Less than $1 / 3$ of all photographs taken along [100], [110] or [1 $1 \overline{1} 0$ ] axes contained evidence of irregular stacking disorder (Fig. 4b). However, HRTEM images almost always revealed some irregular shifts that occur across the B sheets or, less often, across the $\mathrm{T}$ layers.

In an analysis similar to Spinnler et al. (1984), we tried to specify the unique polytypes based on the shift vectors of chlorite projected in [100], [110], or [1/10] direction. Ten HRTEM images from epizonal-grade sample GPB $171 / 61$ taken along the $<100>$ or $<110>$ axes were evaluated with respect to the frequency of different chlorite shift vectors. Based on SAED patterns, the only structural polytype that we could determine was type IIbb. The chlorite shift vectors can be converted into three unique polytypes assuming that only semi-random stacking sequences of the structural polytype IIbb-even occur (see appendix table). The IIba-odd polytypes were not considered because they are equivalent to the polytype IIab by rotation of $180^{\circ}$. This group of polytypes has not been observed in nature. Possible combinations of $\mathrm{T}$ and $\mathrm{B}$ shift vectors can be unequivocally assigned to one of the unique IIbb-even polytypes. The evaluation of the ten HRTEM images show that $55 \%$ of the projected chlorite shift vectors in sample GPB 171/61 belong to the monoclinic polytype IIbb-2, 20\% belong to the triclinic polytype IIbb-4, and $25 \%$ TB units belong to the triclinic chlorite polytype IIbb-6. Because the IIbb-6 polytype is structurally equivalent to the IIbb-4 polytype by a $180^{\circ}$ rotation, sample GPB 171/61 can be considered to consist of 55\% monoclinic IIbb-2 and 45\% triclinic IIbb-4 polytypes. Because the energy difference between these two structures is probably small, further investigations of chlorite stacking sequences may find that most natural type-IIbb chlorites are best described as a mixture of the monoclinic and triclinic IIbb chlorite, especially chlorite from subgreenschist facies samples.

\section{Influences on polytypism and disordering of the stacking sequence}

Several factors are likely to influence layer stacking sequences and polytypism in chlorite over geological time. These are mainly temperature, pressure, composition, crystal growth mechanism, and deformation history.

SAED patterns reveal that two structural polytypes are present in the Taveyanne samples: type-Ibb occurs under diagenetic and anchizonal conditions and type-IIbb polytype is found in rocks at all metamorphic stages (Fig. 4a). Following the polytype transformation sequence proposed by Hayes $\left(1970, \mathrm{Ib}_{\mathrm{d}} \rightarrow \mathrm{Iba} \rightarrow \mathrm{Ibb} \rightarrow \mathrm{IIbb}\right)$, the occurrence of both Ibb and IIbb chlorite suggests that our samples lay in the last transition zone at temperatures around $150-200{ }^{\circ} \mathrm{C}$. Schmidt et al. (1997) noted, however, that sample EP 29 experienced temperatures of at least $270{ }^{\circ} \mathrm{C}$ (Table 1 ), which is significantly higher than predicted by Hayes (1970). Because type-Ibb chlorite is believed to be metastable under all $P$ - $T$ conditions (Bailey 1988), the final transformation from type Ibb to type IIbb depends on kinetic processes and may be influenced by additional factors other than temperature.

The effect of confining pressure may have an important influence on the ordering of the stacking sequence in chlorites as shown by Jullien et al. (1996). Because differences in the total pressure are less pronounced in our study (Table 1), we assume that the effect of confining pressure is much less important than other factors in the Taveyanne Sandstone samples.

Combined AEM analyses and HRTEM images of the same area revealed that pure chlorites from the anchizonal- and epizonal-grade terrains did not show significant differences in composition (Schmidt 1997). Hence, we suggest that compositional variations in chlorites do not have an important influence on the frequency of different polytypes in this study.

HRTEM images indicate that solution-mediated solidstate (SMSS) transformations of sheet silicates have two common features: (1) SMSS transformations tend to preserve the stacking sequence of the precursor material; and (2) SMSS preserves the configuration of pre-existing octahedral sheets, while the cations of the tetrahedral sheets migrate to the reacting chlorite unit. The latter observation is in agreement with previous studies that dealt with the transformation process in sheet silicates (Baronnet 1992; Banfield and Bailey 1996). Dissolution-precipitation reactions may also occur side by side with SMSS processes in sheet silicates from the Taveyanne Sandstone. However, from our data, it is not possible to determine the proportion of the SMSS relative to the dissolution-precipitation mechanism on the chloritization rate in sheet silicates.

It is not apparent that there is any influence of stress upon the chlorites in the Taveyanne Sandstones, although the hand specimens from epizonal regions reveal a strong cleavage. Samples from epizonal-grade areas show a mesoscopically increased strain state relative to lower 
grades, but they have better ordered crystals and fewer intercalations of 0.7 and $1.0 \mathrm{~nm}$ layers in their chlorite packets.

We conclude that the major factor influencing the degree of order and polytype in chlorites is temperature. The higher energy structures, like the presumably metastable Ibb polytype or disordered material, invert with increasing temperature into the regularly ordered IIbb stable polytype. The conclusion is that the relative proportion of the different polytypes is a relative grade indicator. In addition, the occurrence of the metastable Ibb polytype may indicate temperatures $<300^{\circ}$. However, the presence of the stable IIbb polytype has no significance with respect to temperature (see Walker 1993) because it can be found at all grades.

\section{Octahedral vacancies}

Combined computer simulations and HRTEM images from epizonal-grade chlorites indicate that octahedral vacancy clusters are present in the B sheets as well as in the 2:1 T layers. However, vacancy clusters were found only in one sample. Several factors contribute to the difficulty in imaging vacancy clusters. Beside having exactly oriented crystals and a properly aligned column, it is necessary to choose a very thin area, where the chlorite crystal has not been damaged by the ion-milling process or the electron beam. Simulations of various thicknesses of chlorite polytypes calculated along the $<100\rangle$ and $<110>$ direction indicated that the maximum foil thickness for vacancy imaging is probably less than approximately $6.0 \mathrm{~nm}$. In fact, the computer simulations that best matched observed HRTEM images used a thickness of $\sim 3.0 \mathrm{~nm}$ (=3 unit cells in [1 $\overline{1} 0]$ direction). With increasing thickness, no abnormal white spots could be found in the chlorite units of the same specimen. We suppose that a local deficiency of cations can only be imaged if the investigated area is thin. If the sample specimen is too thick, chlorite units with fully occupied sites may overlap with vacant sites that leads to a decrease in vacancy contrast. The ion-milling process may have an influence on the chlorite structure as well. Because vacancies could only be found in the very thin parts of our samples, the vacancy clusters illustrated in Figure 6 are close to the amorphous edge of the ion-milled sample. We cannot rule out the possibility that octahedral cations were extracted during the ion-milling process. However, we suppose that it is unlikely that the ion-milling process removes octahedral cations without creating any tetrahedral vacancies or destroying the adjacent chlorite structure as well.

Comparison of calculated HRTEM images with observed images implies that vacancies are possible in all octahedral positions. However, qualitative observations indicate that the M1 and M2 positions of the T layer are more likely to be vacant as compared to the M3 and M4 positions within the $\mathrm{B}$ sheets. This is in agreement with site occupancies determined for di,tri-octahedral species that place vacancies in the 2:1 octahedral sheet (e.g., Bailey 1988). This also implies that thermodynamic models for chlorite should account for ordering of vacancies into these sites.

\section{ACKNOWLedgments}

We thank M. Frey for his useful comments on the initial draft of this manuscript. We also thank D. Noe whose critical review improved the manuscript. This work was supported by Swiss National Science Foundation, grant no. 20-43122.95/1 and the United States NSF grant EAR948090. The Johns Hopkins High-Resolution and Analytical Electron Microbeam Facility was established by the NSF grants EAR-8300365 and EAR-8606864 and by a grant from the Keck Foundation.

\section{REFERENCES CITED}

Bailey, S.W. (1980) Structures of layer silicates. In G.W. Brindley and G. Brown, Eds., Crystal structures of clay minerals and their X-ray identification, p. 86-98. Mineralogical Society, Monograph, 5, London.

(1988) Chlorites: structures and crystal chemistry. In Mineralogical Society of America Reviews in Mineralogy, 19, 347-403.

Bailey, S.W. and Brown, B.E. (1962) Chlorite polytypism: 1. Regular and semi-random one-layer structures. American Mineralogist, 47, 819850.

Banfield, J.F. and Bailey, S.W. (1996) Formation of regularly interstratified serpentine-chlorite minerals by tetrahedral inversion in long-period serpentine polytypes. American Mineralogist, 81, 79-91.

Baronnet, A. (1992) Polytypism and stacking disorder. In Mineralogical Society of America Reviews in Mineralogy, 27, 231-288.

Bons, A.-J. (1988) Deformation of chlorite in naturally deformed lowgrade rocks. Tectonophysics, 154, 149-165.

Bons, A.-J. and Schryvers, D. (1989) High-resolution electron microscopy of stacking irregularities in chlorites from the central Pyrenees. American Mineralogist, 74, 1113-1123.

Burkhard, M. (1988) L'Helvétique de la bordure occidentale du massif de l'Aar (évolution tectonique et métamorphique). Eclogae Geologicae Helvetiae, 81, 63-114.

Bussy, F. and Epard, J.-L. (1982) Contribution a l'étude minéralogique des gres de Taveyanne des Diablerets au massif de l'Aar. Diploma, Institut de Minéralogie, Université de Lausanne, Switzerland.

(1984) Essai de zonéographie métamorphique entre les Diablerets et le massif de l'Aar (Suisse occidentale), basée sur l'étude des grès de Taveyanne. Schweizerische Mineralogische und Petrographische Mitteilungen, 64, 131-150.

Coombs, D.S., Nakamura, Y., and Vuagnat, M. (1976) Pumpellyite-actinolite facies schists of the Taveyanne formation near Loèche, Valais, Switzerland. Journal of Petrology, 17, 440-471.

Curtis, C.D., Hughes, C.R., Whiteman, J.A., and Whittle, C.K. (1985) Compositional variation within some sedimentary chlorites and some comments on their origin. Mineralogical Magazine, 49, 375-386.

de Caritat, P., Hutcheon, I., and Walshe, J.L. (1993) Chlorite geothermometry: a review. Clays and Clay Minerals, 41, 219-239.

Dietrich, D. and Casey, M. (1989) A new tectonic model for the Helvetic nappes. In M.P. Coward et al., Eds., Alpine Tectonics, 47-63. Elsevier, London.

Hayes, J.B. (1970) Polytypism of chlorite in sedimentary rocks. Clays and Clay Minerals, 18, 285-306.

Jullien, M., Baronnet, A., and Goffé, B., (1996) Ordering of the stacking sequence in cookeite with increasing pressure: An HRTEM study. American Mineralogist, 81, 67-78.

Kisch, H.J. (1980) Illite crystallinity and coal rank associated with lowestgrade metamorphism of the Taveyanne greywacke in the Helvetic zone of the Swiss Alps. Eclogae Geologicae Helvetiae, 73, 753-777.

Kübler, B. (1984) Les indicateurs des transformations physiques et chimiques dans la diagenèse, température et calorimétrie. In M. Lagache, Ed., Thérmométrie et barométrie géologiques, Societé Française de Minéralogie et Cristallographie, Paris, 489-596.

Ramsay, J.G. (1981) Tectonics of the Helvetic nappes. In McClay and N.J. Price, Eds., Thrust and Nappe Tectonics, Special Publication of the Geological Society of London, 9, 293-309.

Schmidt, D. (1997) Very low-grade metamorphism of the Taveyanne for- 
mation, western Helvetic Swiss Alps, 183 p. Ph.D thesis, Mineralogical and Petrological Institute, University of Basel, Switzerland.

Schmidt, D., Schmidt, S.T., Mullis, J., Ferreiro Mählmann, R., and Frey, M. (1997) Very low grade metamorphism of the Taveyanne formation of western Switzerland. Contributions to Mineralogy and Petrology, 129, 385-403.

Spinnler, G.E., Self, P.G., Iijima, S., and Buseck, P.R. (1984) Stacking disorder in clinochlore chlorite. American Mineralogist, 69, 252-263.

Stadelmann, P.A. (1987) EMS-A software package for electron diffraction analysis and HRTEM image simulation in material science. Ultramicroscopy, 21, 131-146.

Veblen, D.R. (1983) Microstructures and mixed layering in intergrown wonesite, chlorite, talc, biotite, and kaolinite. American Mineralogist, $68,566-580$.

Waibel, A.F. (1993) Nature and plate-tectonic significance of orogenic magmatism in the European Alps: a review. Schweizerische Mineralogische und Petrographische Mitteilungen, 73, 391-405.

Walker, J.R. (1989) Polytypism of chlorite in very low grade metamorphic rocks. American Mineralogist, 74, 738-743.

(1993) Chlorite polytype geothermometry. Clays and Clay Minerals, 41, 260-267.

Whittle, C.K. (1986) Comparison of sedimentary chlorite compositions by X-ray diffraction and analytical TEM. Clay Minerals, 21, 937-947.

MAnuscript Received OCtOBer 24, 1997

MANusCript ACCEPTED SePtember 3, 1998

PAPER handled By Jillian F. BANField

\section{Appendix: Computer simulations based on Mac Tempas}

The software program Mac TempasPPC was used for the computer simulations of chlorite structures. HRTEM images of all unique one-layer polytypes were simulated. Computed HRTEM images that were shown in this study were calculated for the polytype IIbb-4, viewing down along the [1 $\overline{1} 0]$ axis direction. Note that the talc-stagger should lie in the (001) plane and its direction should be parallel to $[\overline{1} 00]$. As a consequence, the IIbb-4 polytype was calculated along the [110] direction with atomic parameters as reported by Bailey and Brown (1962). In addition, all HRTEM simulations used a simplified composition $\left(\mathrm{Mg}_{2.5} \mathrm{Fe}_{2.5} \mathrm{Al}\right)\left(\mathrm{Si}_{3} \mathrm{Al}\right) \mathrm{O}_{10}(\mathrm{OH})_{8}$, which is close to the composition determined by EMP technique (Schmidt et al. 1997) in chlorites from the Taveyanne Sandstone. No ordering of tetrahedral and octahedral cations within the $\mathrm{T}$ layer and $\mathrm{B}$ sheet were assumed, except for filling of the M4 octahedral position in the B sheet by Al. The lattice parameters were taken from Bailey (1980). Parameters describing the instrument conditions important for computer simulations were adjusted to agree with the Phillips 420ST microscope. The maximum reciprocal lattice vector in the multislice calculation is $0.20 \mathrm{~nm}^{-1}$; spherical aberration $1.2 \mathrm{~mm}$; the spread of defocus: 5.5 $\mathrm{nm}$; the semi-angle of divergence: $0.5 \mathrm{mrad}$; radius of the objective lens aperture: $0.09 \mathrm{~nm}^{-1}$. A mechanical vibration was introduced and set to $0.1 \mathrm{~nm}$. Except for the through-thickness and through-focus series, all computed images were calculated at a defocus value of $-65.0 \mathrm{~nm}$, which is close to the Scherzer focus and a sample thickness around $3.0 \mathrm{~nm}$. The diameter of the sample thickness correspond to 3 chlorite unit cells viewing down the [1] 0 ] axes.

For defect simulations, a super cell consisting of 3 cells (in [100] direction) $\times 3$ cells (in [010] direction) $\times 3$ cells (in [001] direction) with 1944 atom positions with 2430 atoms of a IIbb-4 chlorite polytype was used to simulate the effect of vacancies on the intensity distribution in HRTEM images.

In Figure 6a the following octahedral atomic positions of $\mathrm{Mg}, \mathrm{Fe}$, and/or Al were removed from the central unit cell to simulate vacancies (atom parameters are given in $[x / y])$ for crystal defect 1 at $z=0.333$ :

$\mathrm{M} 2=0 / 0.111 ; 0 / 0.222 ; 0.167 / 0.277 ; 0.167 / 0.056 ; 0.333 /$ $0.444 ; 0.333 / 0.555 ; 0.5 / 0.611 ; 0.5 / 0.389 ; 0.667 / 0.777$; $0.667 / 0.888 ; 0.833 / 0.944 ; 0.833 / 0.722$;

for crystal defect 2 at $z=0.5$ :

M3 $=0 / 0.055 ; 0 / 0.277 ; 0.167 / 0.222 ; 0.167 / 0.111 ; 0.333 /$ $0.389 ; 0.333 / 0.611 ; 0.5 / 0.555 ; 0.5 / 0.444 ; 0.667 / 0.722$; 0.667/0.944; 0.833/0.889; 0.833/0.777; M4 50\%: 0/0.167; $0.333 / 0.5 ; 0.667 / 0.833$.

In Figure 6b, following octahedral atomic positions of $\mathrm{Mg}$ and Fe were subtracted (atom parameters $[x / y]$ ) at crystal defect for $z=0.333$ :

$\mathrm{M} 1=0 / 0 ; 0.167 / 0.167 ; 0.333 / 0.333 ; 0.5 / 0.5 ; 0.667 /$ $0.667 ; 0.833 / 0.833 ; \mathrm{M} 2=0 / 0.111 ; 0 / 0.222 ; 0.167 / 0.277$; $0.167 / 0.056 ; 0.333 / 0.444 ; 0.333 / 0.555 ; 0.5 / 0.611 ; 0.5 /$ $0.389 ; 0.667 / 0.777 ; 0.667 / 0.888 ; 0.833 / 0.944 ; 0.833 /$ 0.722 .

Appendix Table 1. Projection of the one-layer polytypes as seen down the [100], [110], and [1 $1 \overline{1} 0]$ axes (modified after Spinnler et al. 1984)

\begin{tabular}{llll}
\hline \hline \multicolumn{1}{c}{$\begin{array}{c}\text { One-layer } \\
\text { polytype }\end{array}$} & {$[100]$} & {$[110]$} & {$[1 \overline{1} 0]$} \\
\hline lab-1 & $\mathrm{T}_{0} \mathrm{~B}_{0}$ & $\mathrm{~T}_{+} \mathrm{B}_{+}$ & $\mathrm{T}_{-} \mathrm{B}_{-}$ \\
laa-2 & $\mathrm{T}_{0} \mathrm{~B}_{0}$ & $\mathrm{~T}_{+} \mathrm{B}_{0}$ & $\mathrm{~T}_{-} \mathrm{B}_{0}$ \\
lab-3 & $\mathrm{T}_{0} \mathrm{~B}_{-}$ & $\mathrm{T}_{+} \mathrm{B}_{-}$ & $\mathrm{T}_{-} \mathrm{B}_{0}$ \\
laa-4 & $\mathrm{T}_{0} \mathrm{~B}_{-}$ & $\mathrm{T}_{+} \mathrm{B}_{+}$ & $\mathrm{T}_{-} \mathrm{B}_{+}$ \\
lab-5 & $\mathrm{T}_{0} \mathrm{~B}_{+}$ & $\mathrm{T}_{+} \mathrm{B}_{0}$ & $\mathrm{~T}_{-} \mathrm{B}_{+}$ \\
laa-6 & $\mathrm{T}_{0} \mathrm{~B}_{+}$ & $\mathrm{T}_{+} \mathrm{B}_{-}$ & $\mathrm{T}_{-} \mathrm{B}_{-}$ \\
llaa-1 & $\mathrm{T}_{0} \mathrm{~B}_{0}$ & $\mathrm{~T}_{+} \mathrm{B}_{0}$ & $\mathrm{~T}_{-} \mathrm{B}_{0}$ \\
llab-2 & $\mathrm{T}_{0} \mathrm{~B}_{0}$ & $\mathrm{~T}_{+} \mathrm{B}_{-}$ & $\mathrm{T}_{-} \mathrm{B}_{+}$ \\
llaa-3 & $\mathrm{T}_{0} \mathrm{~B}_{-}$ & $\mathrm{T}_{+} \mathrm{B}_{+}$ & $\mathrm{T}_{-} \mathrm{B}_{+}$ \\
llab-4 & $\mathrm{T}_{0} \mathrm{~B}_{-}$ & $\mathrm{T}_{+} \mathrm{B}_{0}$ & $\mathrm{~T}_{-} \mathrm{B}_{-}$ \\
llaa-5 & $\mathrm{T}_{0} \mathrm{~B}_{+}$ & $\mathrm{T}_{+} \mathrm{B}_{-}$ & $\mathrm{T}_{-} \mathrm{B}_{-}$ \\
llab-6 & $\mathrm{T}_{0} \mathrm{~B}_{+}$ & $\mathrm{T}_{+} \mathrm{B}_{+}$ & $\mathrm{T}_{-} \mathrm{B}_{0}$ \\
lbb-1, Ilba-1 & $\mathrm{T}_{0} \mathrm{~B}_{0}$ & $\mathrm{~T}_{+} \mathrm{B}_{-}$ & $\mathrm{T}_{-} \mathrm{B}_{+}$ \\
lba-2, Ilbb-2 & $\mathrm{T}_{0} \mathrm{~B}_{0}$ & $\mathrm{~T}_{+} \mathrm{B}_{+}$ & $\mathrm{T}_{-} \mathrm{B}_{-}$ \\
lbb-3, Ilba-3 & $\mathrm{T}_{0} \mathrm{~B}_{-}$ & $\mathrm{T}_{+} \mathrm{B}_{0}$ & $\mathrm{~T}_{-} \mathrm{B}_{-}$ \\
lba-4, Ilbb-4 & $\mathrm{T}_{0} \mathrm{~B}_{-}$ & $\mathrm{T}_{+} \mathrm{B}_{-}$ & $\mathrm{T}_{-} \mathrm{B}_{0}$ \\
lbb-5, Ilba-5 & $\mathrm{T}_{0} \mathrm{~B}_{+}$ & $\mathrm{T}_{+} \mathrm{B}_{+}$ & $\mathrm{T}_{-} \mathrm{B}_{0}$ \\
lba-6, Ilbb-6 & $\mathrm{T}_{0} \mathrm{~B}_{+}$ & $\mathrm{T}_{+} \mathrm{B}_{0}$ & $\mathrm{~T}_{-} \mathrm{B}_{+}$ \\
\hline
\end{tabular}

